\title{
Marking of temporal point and lower border of temporal triangle in planning hair transplantation for male-pattern baldness
}

\author{
Suneet Soni, Hardik Dodia ${ }^{1}$ \\ Medispa Laser and Cosmetic Surgery Centre, Jaipur, Rajasthan, ${ }^{1}$ Department of Burns and Plastic Surgery, B.J. Medical \\ College, Gujarat University, Ahmedabad, Gujarat, India
}

Address for correspondence: Dr. Hardik Dodia, Department of Burns and Plastic Surgery, B.J. Medical College, Gujarat University, Ahmedabad, Gujarat, India. E-mail: hardikdodia008@gmail.com

\section{ABSTRACT}

Introduction: Temporal recession in male-pattern baldness is common. The method of marking of temporal point practiced worldwide, described by Walter P. Unger, does not help in marking temporal triangle border in Indian population. We have found aesthetically superior way of marking temporal point and easy method of construction of lower border of temporal triangle. Case Series: The new marking was applied over 126 young male patients from March 2014 to December 2017; they were regularly followed up and results were observed. Conclusion: With the new method of marking, we found that the lower border of temporal triangle can be easily constructed and temporal point can be more aesthetically placed in Indian population.

\section{KEY WORDS}

Follicular unit transplantation; hair transplantation; male-pattern baldness; temporal point marking; temporal triangle construction

\section{INTRODUCTION}

sian population has more rounded face and head compared to the Western population. The method of marking of temporal point practiced worldwide, described by Walter P. Unger, does not help in marking temporal triangle border in Indian population. Hair transplant is a commonly performed procedure nowadays in India. There are no specific design guidelines in Asian population, So we follow guidelines

\begin{tabular}{|l|l|}
\hline \multicolumn{2}{|c|}{ Access this article online } \\
\hline Quick Response Code: & Website: \\
\hline
\end{tabular}

for Western population as described by Walter P. Unger. Hair transplant is more of art than science. We have tried to modify the design of temporal triangle in this study.

Temporal recession in male-pattern baldness is common. Grades of temporal point recession ${ }^{[1]}$ are as follows:

$\mathrm{N}=$ No thinning or recession of temporal point hair

This is an open access journal, and articles are distributed under the terms of the Creative Commons Attribution-NonCommercial-ShareAlike 4.0 License, which allows others to remix, tweak, and build upon the work non-commercially, as long as appropriate credit is given and the new creations are licensed under the identical terms.

For reprints contact: reprints@medknow.com

How to cite this article: Soni S, Dodia H. Marking of temporal point and lower border of temporal triangle in planning hair transplantation for male-pattern baldness. Indian J Plast Surg 2018;51:316-20. 
$\mathrm{T}=$ Thinning and/or mild recession

$\mathrm{P}=$ Apex of recession is parallel to the anterior sideburn line

$\mathrm{R}=$ Recession has caused a reversed angle that is usually anteriorly convex, but is now concave.

This straightforward classification uses letters N, T, P and $\mathrm{R}$, which are added in brackets after the usual Norwood classification in brackets like $4 \mathrm{~T}$ or $6 \mathrm{P}^{[2-4]}$

Patients with Class $\mathrm{N}$ or $\mathrm{T}$ usually require no augmentation. Classes $\mathrm{P}$ and $\mathrm{R}$ require surgical augmentation [Figures 1-4].

The usual balance of temporal point with the frontal hairline is to place it where the following two lines intersect. Line A is drawn from the most anterior part of

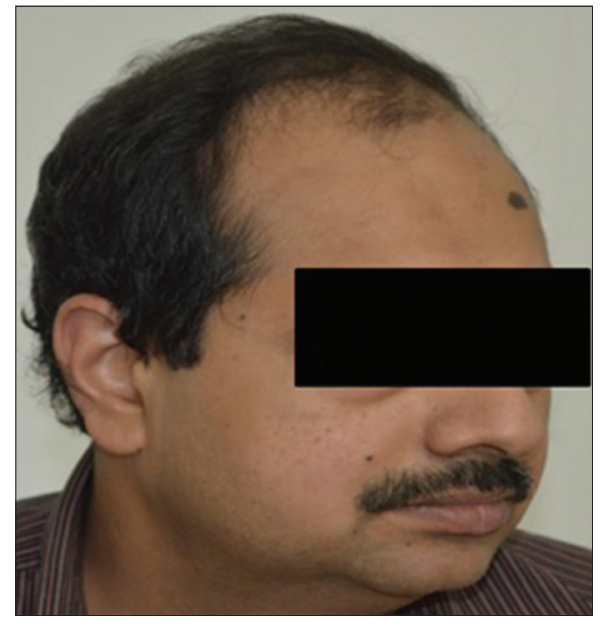

Figure 1: Grade N

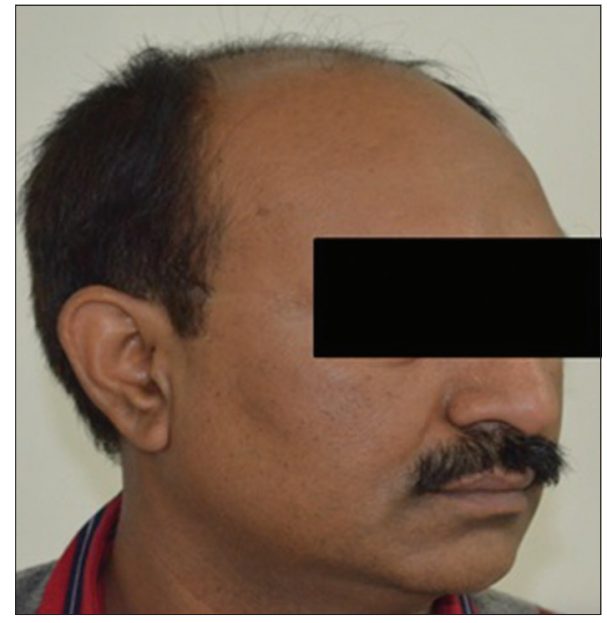

Figure 3: Grade P the hairline to the tip of the ear lobe. Line B is drawn from the tip of the nose, over the centre of the pupil to the anterior temporal point. ${ }^{[1]}$ In Indian population where the face is little more round and short than that of Caucasian population, this new temporal line suits better.

Conventional line drawings for temporal point are depicted in Figures 5 and 6.

\section{Aims and objectives}

The aims and objectives of the study were as follows:

- To facilitate easy marking of temporal triangle

- To define the temporal point more aesthetically

- Mark lower border of the triangle easily.

\section{MATERIALS AND METHODS}

The study was carried out at author's private setup.

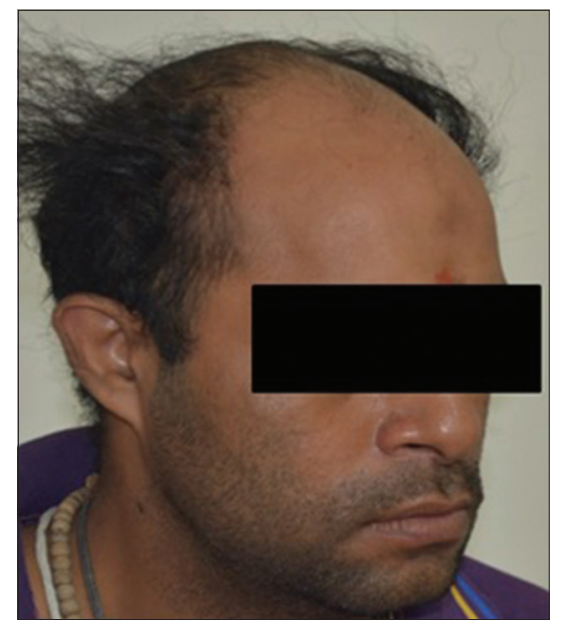

Figure 2: Grade T

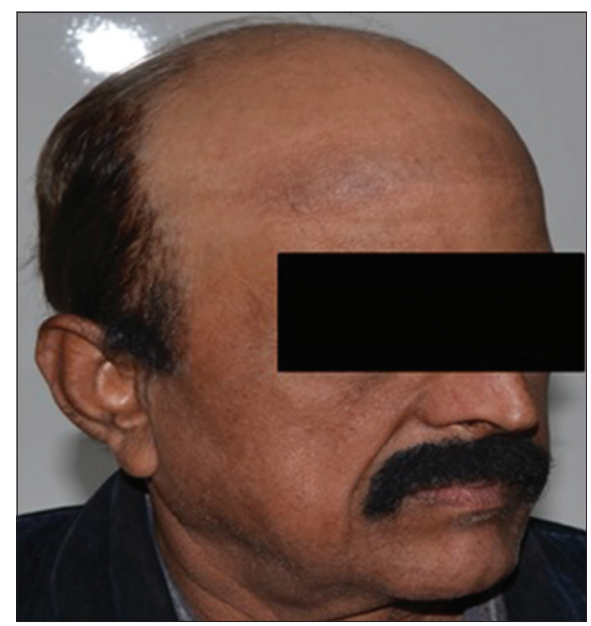

Figure 4: Grade R 
The new marking was applied on 126 patients from March 2014 to December 2017; they were regularly followed up and results were observed.

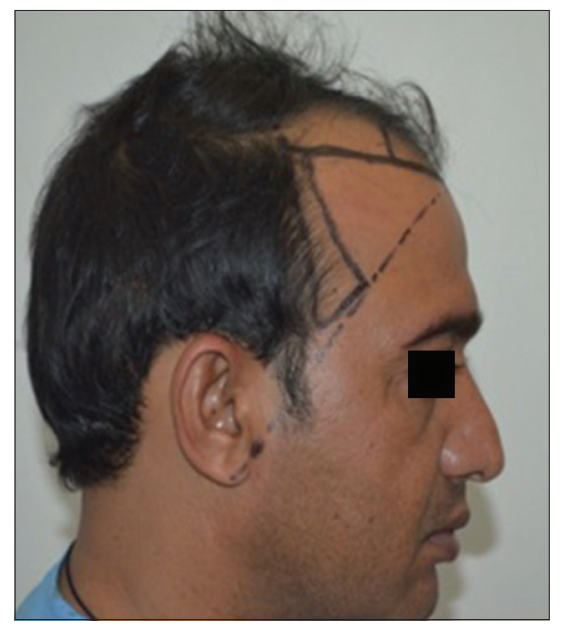

Figure 5: Line A

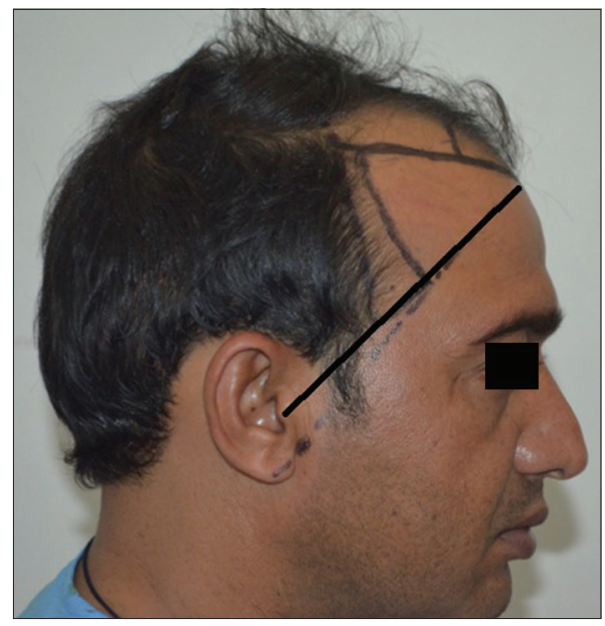

Figure 7: New marking and lower border of the temporal triangle in patient 1

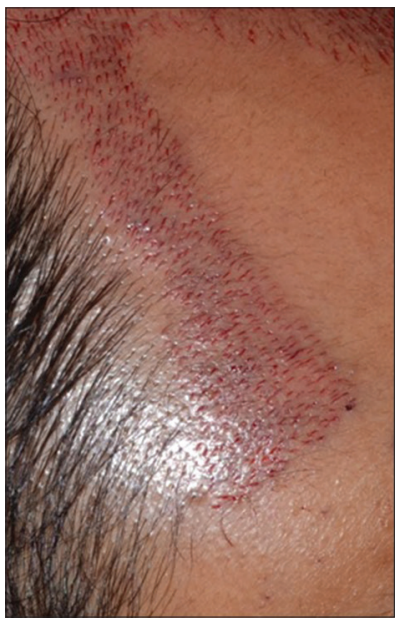

Figure 9: Post marking punching in patient 2

\section{Observation}

The following is the new marking of the lower border of temporal triangle:

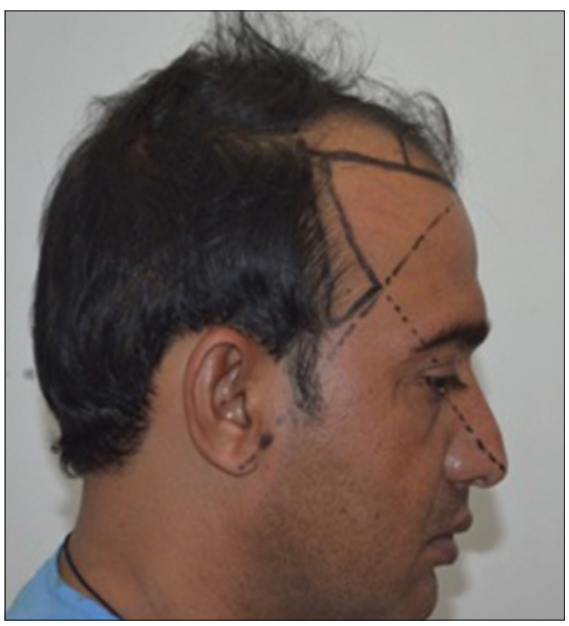

Figure 6: Line B

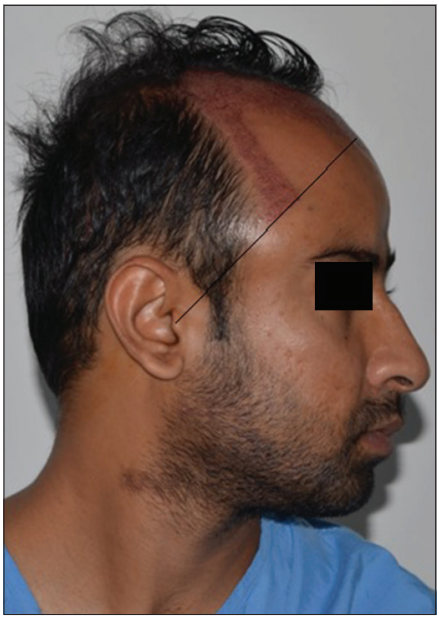

Figure 8: New marking and lower border of the temporal triangle in patient 2

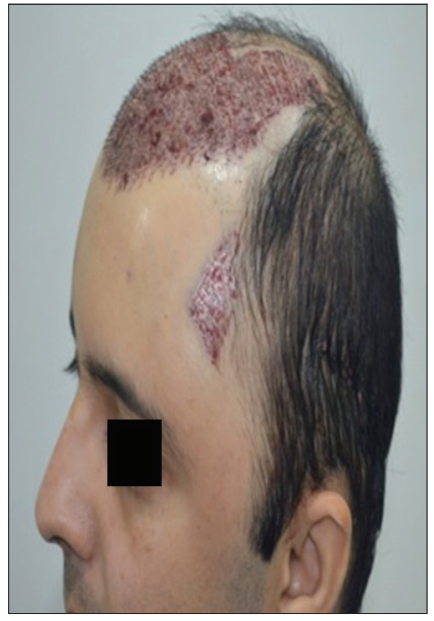

Figure 10: Punching with new marking in patient 3 
Line A: Drawn from the most anterior part of the hairline to the tragus of ear

Line B: Drawn from the tip of the nose, over the centre of the pupil to the anterior temporal point..$^{[3]}$

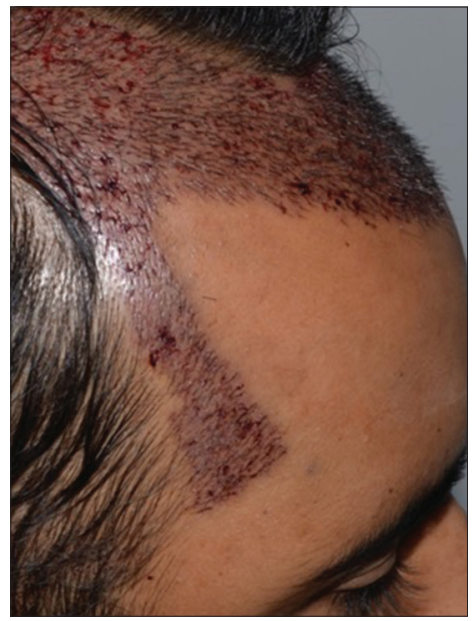

Figure 11: Punching with new marking in Patient 4

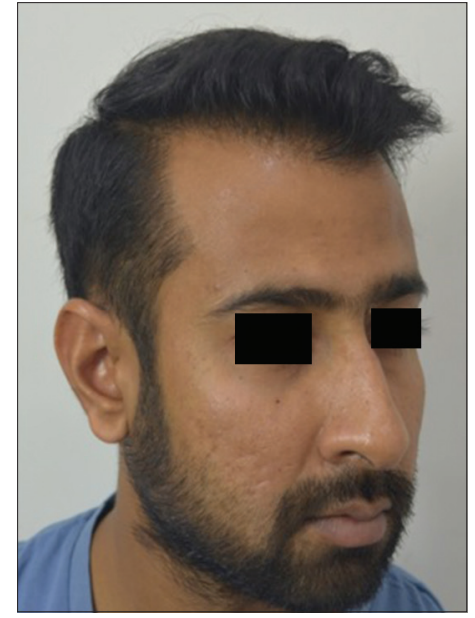

Figure 13: Result in patient 2

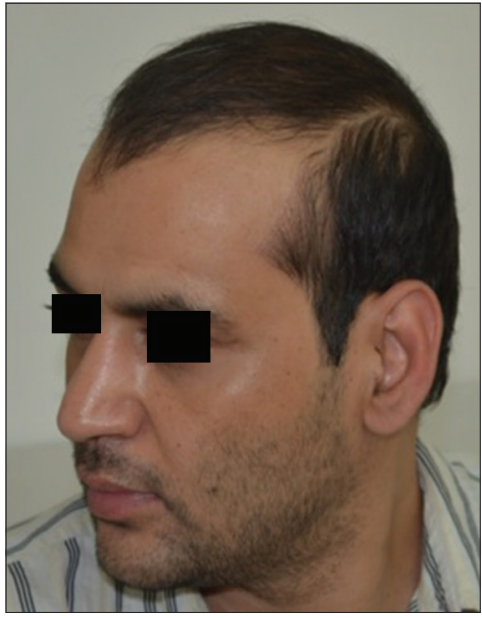

Figure 15: Result of another patient with same marking principle
The new proposed temporal line is depicted in Figure 7.

The new line A compared to the old line A helps in forming the lower border of the temporal triangle and

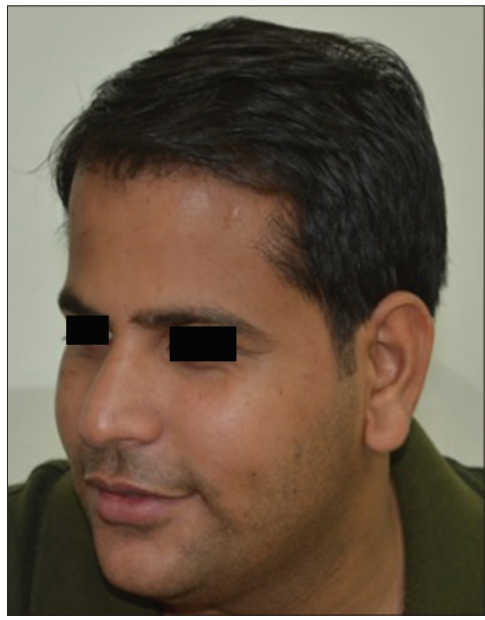

Figure 12: Result in patient 4

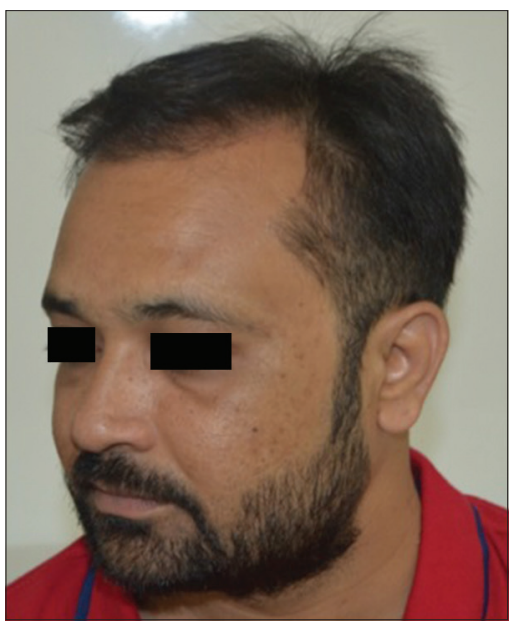

Figure 14: Result of another patient with same marking principle

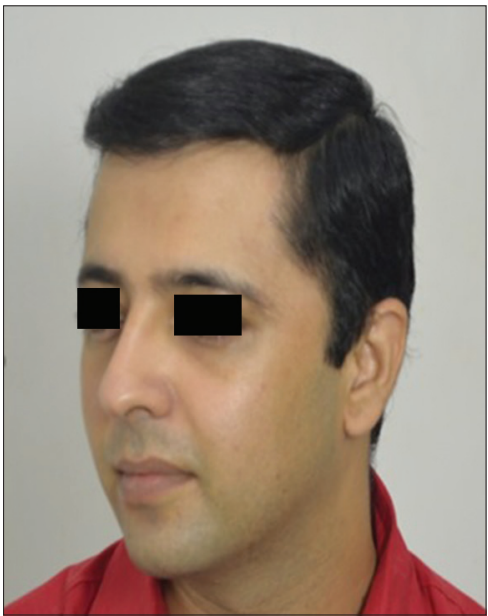

Figure 16: Result in patient 3 
helps in more aesthetic allocation of temporal point slightly above the previous line [Figures 8-12].

Satisfactory results were obtained. With this method, the temporalpointcanbemoreaestheticallyplacedand thelower border of the temporal triangle can be easily constructed more aesthetically in Indian population [Figures 13-16].

\section{DISCUSSION}

The technique for temporal triangle reconstruction as mentioned by Walter P. Unger is universally followed, and is aesthetically better in western population as they have long face. While the technique mentioned in this study is aesthetically better for Indian population, a slight higher shift of the lower border of temporal triangle is aesthetically better in round face which is found in Asians.

In a study by Shapiro and Shapiro on hairline design and frontal hairline restoration, ${ }^{[1]}$ the authors mentioned to keep the lower border of the temporal triangle slightly above the line formed by drawing triangle but did not mention to change the point from ear lobule to tragus. However, if we change the point from ear lobule to tragus, the same line can be obtained.

\section{CONCLUSION}

With the new method of marking, we found that the lower border of temporal triangle can be more aesthetically placed in Indian population.

\section{Financial support and sponsorship}

Nil.

\section{Conflicts of interest}

There are no conflicts of interest.

\section{REFERENCES}

1. Shapiro R, Shapiro P. Hairline design and frontal hairline restoration. Facial Plast Surg Clin North Am 2013;21:351-62.

2. Shapiro R. Creating a natural hairline in one session using a systemic approach and modern principles of hairline design. Int J Cosmet Surg Aesthet Dermatol 2001;3:89-99.

3. Unger W. Hairline zone. In: Unger W, Shapiro R, editors. Hair Transplantation. $5^{\text {th }}$ ed., Ch. 6 A. London: Informa Healthcare: Informa; 2011. p. 133-40.

4. Shapiro R. How to use follicular unit transplantation in the hairline and other appropriate areas. In: Unger WP, Shapiro R, editors. Hair Transplantation. $4^{\text {th }}$ ed. New York: Marcel Dekker; 2004. p. 454-69. 